\title{
Natural killer T cells and the regulation of asthma
}

\author{
P Matangkasombut $^{1,2}$, M Pichavant $^{1}, \mathrm{RH}$ DeKruyff $^{1}$ and DT Umetsu ${ }^{1}$
}

\begin{abstract}
A crucial role has been suggested for invariant natural killer T cells (iNKT) in regulating the development of asthma, a complex and heterogeneous disease characterized by airway inflammation and airway hyperreactivity (AHR). iNKT cells constitute a unique subset of $\mathrm{T}$ cells responding to endogenous and exogenous lipid antigens, rapidly secreting a large amount of cytokines, which amplify both innate and adaptive immunity. Herein, we review recent studies showing a requirement for iNKT cells in various models of asthma in mice and monkeys as well as studies in human patients. Surprisingly, in several different murine models of asthma, distinct subsets of iNKT cells were required, suggesting that iNKT cells serve as a common critical pathogenic element for many different forms of asthma. The importance of iNKT cells in both allergic and non-allergic forms of asthma, which are independent of adaptive immunity and associated with airway neutrophils, may explain situations previously found to be incompatible with the Th2 paradigm of asthma.
\end{abstract}

\section{INTRODUCTION}

Bronchial asthma, which affects almost $10 \%$ of the general population, ${ }^{1-3}$ is a complex and heterogeneous inflammatory disorder of the airways involving an interplay between environmental factors and as many as 100 major and minor susceptibility genes. ${ }^{4-6}$ The heterogeneity of the disease has been recognized for years, and many distinct forms of asthma exist, including allergic asthma (the most common form), as well as other forms induced by exercise, aspirin, air pollution, or viral infection. In susceptible individuals, these environmental factors cause recurrent episodes of wheezing, breathlessness, chest tightness, and coughing associated with reversible airflow obstruction of varying degrees of severity. ${ }^{7}$ Airway hyperreactivity (AHR), which correlates with the severity of asthma, is another important feature of asthma, resulting in increased symptoms on exposure to various nonspecific stimuli (Box 1). Currently available controller medications for asthma (corticosteroids, leukotriene antagonists, anti-IgE, and mast cell stabilizers) and novel therapeutics being tested in clinical trials (anti-interleukin (IL)-4, anti-IL-13, and anti-IL-5 antibodies) focus on reducing airway inflammation, particularly inflammation driven by Thelper (Th)2 lymphocytes. Corticosteroids and $\beta 2$ agonists constitute the main stay of therapy, but as many as $10-30 \%$ of patients do not respond to therapy, and asthma remains the most common chronic disease of childhood. The absence of effective and curative therapies for asthma suggests that our understanding of the disease mechanisms in asthma is inadequate. In this review, we will discuss a new paradigm for the pathogenesis of asthma, in which natural killer T cells (NKT cells) have been proposed as an important effector cell type for this disease.

\section{INFLAMMATION IN ASTHMA}

Antigen-specific Th2 cells are believed to have a central role in asthma, orchestrating airway inflammation by secreting cytokines such as IL-4, IL-13, IL-5, and IL-9. These cytokines increase the production of IgE, levels of which correlate with disease, ${ }^{8}$ increase eosinophil, basophil, and mast cell recruitment, growth and differentiation, and directly affect airway smooth muscle and mucous glands, resulting in AHR. ${ }^{1,9} \mathrm{CD} 4^{+}$ Th2 cells are believed to be present in the lungs of most patients with asthma, particularly those with allergic asthma, ${ }^{10}$ and allergen sensitization, a consequence of developing allergen-specific $\mathrm{CD} 4^{+} \mathrm{Th} 2$ cells, is a major risk factor for the development of asthma. ${ }^{11,12}$ Moreover, in animal models of allergic asthma, depletion of $\mathrm{CD} 44^{+} \mathrm{T}$ cells prevents the development of AHR, ${ }^{13}$ suggesting that Th2 cells have an indispensable role in disease pathogenesis.

Although the presence of Th2 cells and eosinophils can explain many features of allergic asthma, ${ }^{10,14}$ this paradigm cannot account for many observations in asthma. ${ }^{6}$ First, the Th2 paradigm cannot explain non-allergic asthma, induced with exercise, aspirin, viral infection, or air pollution, which is often associated with airway neutrophils rather than eosinophils.

\footnotetext{
${ }^{1}$ Division of Immunology and Allergy, Department of Pediatrics, Children's Hospital Boston, Harvard Medical School, Boston, Massachusetts, USA. ${ }^{2}$ Department of Immunology and Infectious Diseases, Harvard School of Public Health, Boston, Massachusetts, USA. Correspondence: DT Umetsu (dale.umetsu@childrens.harvard.edu) 


\section{Box 1 Airway hyperreactivity (AHR)}

Airway hyperreactivity is a cardinal feature of asthma, because it is present in all forms of asthma and correlates well with the disease severity. In experimental asthma models, AHR is the most important outcome and can be measured by the loss of pulmonary function with increasing doses of an inhaled provocative stimulus, such as methacholine or histamine. Greater loss of pulmonary function with smaller doses of stimulus indicates greater AHR.

Second, treatments that target or eliminate Th2 cells and their cytokines (e.g., anti-IL-4, anti-IL-5 antibodies (Abs) or IL-4/IL13 antagonists) have not reduced AHR in numerous clinical trials for asthma, ${ }^{15,16}$ suggesting that other immunological factors, in addition to Th 2 cells, may critically regulate asthma. Third, most patients with allergic rhinitis and allergen sensitization do not have asthma, ${ }^{17}$ suggesting that the presence of Th2 cells and allergen-specific IgE per se, is not sufficient for the development of asthma. Finally, elevated levels of non-Th2 cytokines and factors, such as interferon- $\gamma($ IFN- $\gamma),{ }^{18,19} \mathrm{IL}-17,{ }^{20-22}$ and neutrophils, ${ }^{23-25}$ are frequently present in the lungs of asthmatics, particularly in patients with severe disease, or with corticosteroid resistant asthma. ${ }^{26,27}$ Taken together, these observations suggest that other pathways beyond Th2 cells and eosinophils contribute to the development of the asthma phenotype. ${ }^{6}$

\section{NKT CELLS}

One cell type that has been proposed to contribute immensely to the development of asthma is NKT cells, which constitute a small population of lymphocytes that express markers of both T cells (T-cell receptor, TCR) and NK cells (e.g., NK1.1, NKG2D). NKT cells can be subdivided into at least three subtypes, based on their TCR. Type I NKT cells or invariant NKT (iNKT) cells express invariant TCR $\alpha$ chains (V $\alpha 14-\mathrm{J} \alpha 18$ in mice and $V \alpha 24-J \alpha 18$ in humans) coupled with a limited repertoire of $\mathrm{V} \beta$ chains $(\mathrm{V} \beta 8, \mathrm{~V} \beta 7$ and $\mathrm{V} \beta 2$ in mice and $\mathrm{V} \beta 11$ in humans). Type I NKT cells respond to glycolipid antigens presented in the context of the non-polymorphic major histocompatibility complex (MHC) class I-like molecule CD1d. In all mammals except ruminants, ${ }^{28,29}$ Type I NKT cells are present and respond to the glycolipid $\alpha$-galactosylceramide $\left(\alpha\right.$-GalCer), ${ }^{30,31}$ showing a great evolutionary conservation of the invariant TCR, which most likely represents a pattern recognition receptor.

Type II NKT cells also recognize glycolipid antigens presented by CD1d, but these NKT cells express non-invariant (heterogeneous) TCRs. Type III NKT cells express non-invariant TCRs and recognize antigen in a CD1d-independent manner. The study of Type I iNKT cells has progressed rapidly over the past 5 years, as reagents to identify and study Type I iNKT cells (NKT-cell-deficient mice and CD1d tetramers) have become available.

The conserved, invariant TCR of iNKT cells appears to function as a pattern recognition receptor, ${ }^{32}$ suggesting that iNKT cells serve as a component of innate immunity. Upon activation, iNKT cells rapidly secrete a large amount of Th1 and Th2 cytokines and chemokines, which then activates DCs, macrophages, NK cells, T cells, and B cells, and drives the development of adaptive immunity. ${ }^{33}$ iNKT cells also express features of NK cells, producing perforin and granzyme
B. ${ }^{34-36}$ iNKT cells can be further categorized into $\mathrm{CD} 4^{+}$and double-negative (DN) subsets, with the $\mathrm{CD}^{+}$subset producing greater amounts of IL- 4 and IL-13 than the DN iNKT cells. The DN iNKT cell subset includes iNKT cells that produce IL-17 and IL-22, which may have an important role in the lungs (see below). Furthermore, as iNKT cells cultured with transforming growth factor- $\beta$ express Foxp 3 and produce IL-10, a marker of regulatory T cells, it is likely that a regulatory subset of iNKT cells also exists (M. Leite-de-Moraes and M. Monteiro, 5th International Symposium on CD1/NKT cells, 2009, Kamakura, Japan). The broad spectrum of cytokines secreted by iNKT cells may explain their implication in multiple diseases, including infectious diseases, ${ }^{37,38}$ malignancy, ${ }^{39}$ autoimmune diseases ${ }^{40}$ (diabetes, lupus, colitis), allograft rejection, ${ }^{41}$ atherosclerosis, ${ }^{42}$ and asthma. ${ }^{43}$ The many distinct functions of iNKT cells suggest that various subsets of iNKT cells exist, each producing a different profile of cytokines, or that the cytokine profile produced by the iNKT cells can be modulated by extrinsic factors.

THE ROLE OF INKT CELLS IN MURINE MODELS OF ASTHMA A crucial role of iNKT cells in the development of asthmalike symptom has been shown in several murine models of asthma.

\section{Allergen-induced AHR}

In 2003 , we and others ${ }^{44,45}$ showed a role for iNKT cells in a model of allergic asthma, associated with Th2 responses, eosinophils, and AHR. Both J $\alpha 18^{-1-}$ and CD $1 \mathrm{~d}^{-/-}$mice, which lack iNKT cells, failed to develop allergen-induced AHR and had reduced airway inflammation after airway challenge with ovalbumin (OVA). Adoptive transfer of wild-type but not IL-4/ IL-13-1- iNKT cells into J $\alpha 18^{-/-}$mice fully restored AHR and airway inflammation, showing the requirement of iNKT cells for the development of allergen-induced AHR. Furthermore, administration of recombinant IL- 13 to $\mathrm{CD} 1 \mathrm{~d}^{-/-}$mice elicited AHR, indicating that the CD1d ${ }^{-/-}$mice do not have an intrinsic inability to develop AHR. A varying degree of allergen-induced airway eosinophilia occurred in the absence of iNKT cells, from markedly reduced in some studies ${ }^{44,48}$ to slightly reduced in others in comparison with wild-type mice. ${ }^{46,47}$ AHR, arguably the most critical feature of asthma, always failed to occur in the absence of iNKT cells. ${ }^{44,45}$ Importantly, the iNKT-celldeficient mice developed normal Th2 responses, ${ }^{49}$ indicating that iNKT cells are not absolutely required for the development of Th2 responses and that Th2 cells, required for the response to protein allergens, are not sufficient for the development of AHR. ${ }^{44,45}$ Taken together, these studies indicate that both Th2 cells (necessary for allergen-specific responses) and iNKT cells producing IL-4 and IL-13 are required for the development of allergen-induced AHR. However, the exact mechanisms by which iNKT cells collaborate with Th2 cells in the development of allergen-induced AHR remains unclear, and may involve amplification of Th2 responses, or the massive production by iNKT cells of Th2 cytokines, particularly IL-13, which triggers AHR. 


\section{Ozone-induced AHR}

A requirement for iNKT cells has also been shown in a model of asthma induced with air pollution, a known trigger of asthma symptoms. ${ }^{50,51}$ In this model, mice repeatedly exposed to ozone, a major component of air pollution, developed severe AHR and airway inflammation. ${ }^{22}$ Unlike allergen-induced AHR, which is associated with airway eosinophils, ozone-induced AHR was associated with airway neutrophils and macrophages. $^{22}$ Importantly, both CD1d ${ }^{-/-}$and $\mathrm{J} \alpha 18^{-/-}$failed to develop ozone-induced AHR, indicating that iNKT cells were required for the development of ozone-induced AHR. Moreover, IL-17 $\mathrm{A}^{-1-}$ mice failed to develop ozone-induced AHR, although they developed severe allergen-induced AHR, indicating that IL-17 was specifically required for ozone- but not for allergen-induced AHR. As MHC class II-deficient mice, which lack conventional CD $4{ }^{+} \mathrm{T}$ cells but have iNKT cells, developed ozone-induced AHR, iNKT cells but not conventional CD4 ${ }^{+} \mathrm{T}$ cells (Th17 cells) produced IL-17, required for the development of ozone-induced AHR. Indeed, a unique NK1.1 ${ }^{-} \mathrm{IL}-17^{+}$iNKT cell subset was present in the lungs of ozone-exposed mice, suggesting that ozone-induced AHR required a subset of iNKT cells distinct from that required for allergen-induced AHR. These iNKT cells require ROR $\gamma \mathrm{T}$ for development, constitutively express IL-23 receptor, ${ }^{52}$ produce IL-22, and have been identified in situations associated with neutrophilic inflammation. ${ }^{53-56}$ However, IL-17 produced by other MHC class II-independent cells such as $\gamma \delta$ T cells could also have a role in this system. Nevertheless, as ozone-induced AHR developed in MHC class II-deficient mice, ${ }^{22}$ these studies show that AHR can occur in the complete absence of Th2 cells and adaptive immunity.

\section{Virus-induced AHR and chronic lung disease}

A requirement for iNKT cells has also been shown in a third model of AHR, induced with respiratory viruses, which trigger asthma symptoms in virtually all patients with asthma, ${ }^{57-59}$ although the precise immunological mechanisms by which viruses cause asthma have not been understood earlier. Using Sendai virus, which is related to human viruses that are clinically important (respiratory syncytial virus and parainfluenza virus), Kim et al. ${ }^{60}$ showed that viral infection induced acute bronchiolar inflammation, followed by a delayed but permanent chronic phase of mucous cell metaplasia and increased AHR, resembling human chronic lung disease (asthma and chronic obstructive pulmonary disease). Surprisingly, the AHR and airway inflammatory response required the presence of $\mathrm{CD} 4^{-}$iNKT cells, and failed to occur in CD $1 \mathrm{~d}^{-/-}$and $\mathrm{J} \alpha 18^{-/-}$mice. In this model, the iNKT cells induced alternatively activated macrophages, which produced IL-13, which in turn drove increased mucus production and AHR. As the virus-induced AHR response occurred in $\mathrm{MHC}$ class $\mathrm{II}^{-/-}$mice, adaptive immunity was not required for the development of this form of AHR. These findings provide new insight into the pathogenesis of virus-induced inflammatory airways diseases and show the requirement for a novel subset of iNKT cells, and an iNKT cell-alternatively activated IL-13-producing macrophage innate immune axis.

\section{SUBSETS OF INKT CELLS IN ASTHMA}

The studies in three different models of asthma induced with allergen, ozone, and viral infection suggest that iNKT cells may provide a common disease mechanism for many different forms of asthma, including asthma that occurs in the absence of adaptive immunity and in association with neutrophils. Moreover, these studies indicate that distinct subsets of iNKT cells are involved in different forms of asthma (Table 1). Although $\mathrm{CD}^{+}{ }^{+} \mathrm{IL}-4 / \mathrm{IL}-13$-producing iNKT cells (in concert with antigen-specific Th2 cells) are crucial in allergen-induced AHR, NK1.1 ${ }^{-}$IL-17-producing iNKT cells have a major role in ozoneinduced $\mathrm{AHR}$, and $\mathrm{CD}^{-}{ }^{-}$iNKT are involved in respiratory virus-induced AHR.

\section{ARE iNKT CELLS REQUIRED IN ALL MOUSE MODELS OF AHR?}

Although iNKT cells have been shown to be clearly required for the development of AHR in at least three distinct models of asthma (see above), several studies suggested that iNKT cells might not be important for the development of AHR in some cases. In the first of these studies, published more than 10 years ago, $\beta 2$ microglobulin-deficient $\left(\beta 2 \mathrm{~m}^{-/-}\right)$mice, which were believed not to have iNKT cells, in fact developed severe allergen-induced AHR. ${ }^{61,62}$ As CD1d is a heterodimeric molecule that includes $\beta 2 \mathrm{~m}, \beta 2 \mathrm{~m}^{-/-}$mice were believed to lack CD1d, and also to lack CD1d-restricted cells, including iNKT cells. However, subsequent studies showed that CD1d can be expressed in the absence of $\beta 2 \mathrm{~m} .{ }^{63-66}$ Moreover, NK1.1 ${ }^{+}, \mathrm{TCR}^{+}$

Table 1 The involvement of iNKT cells subsets in different murine asthma models

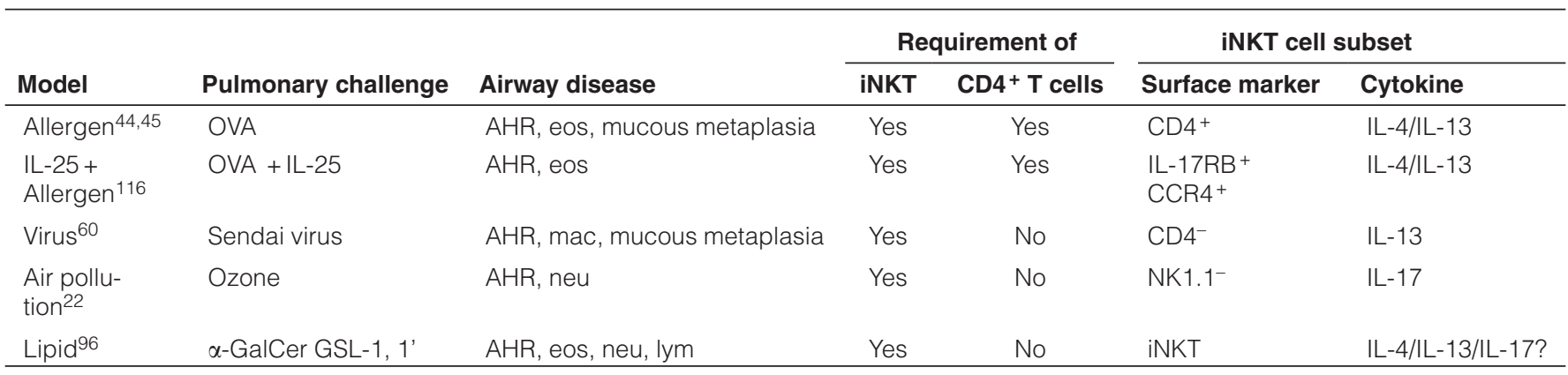

AHR, airway hyperreactivity; eos, eosinophils; $\alpha$-GalCer, $\alpha$-galactosylceramide; GSL-1,1', sphingomonas glycosphingolipids; IL, interleukin; iNKT, invariant natural killer T cells; lym, lymphocytes; mac, macrophages; neu, neutrophils; OVA, ovalbumin. 
NKT cells are in fact present in $\beta 2 \mathrm{~m}^{-/-}$mice. ${ }^{63,67,68}$ In addition, AHR in these mice was abolished by treatment with an anti-CD1d blocking $\mathrm{mAb}$ and by treatment with an anti-NK1.1 $\mathrm{mAb}$ (depletes NK and NKT cells), but not with anti-asialo GM1 $\mathrm{Ab}$ (depletes only NK cells and not NKT cells). ${ }^{68}$ Furthermore, allergen-induced AHR was restored in $\mathrm{CD} 1 \mathrm{~d}^{-/-}$mice by adoptive transfer of an NKT-cell-enriched population from $\beta 2 \mathrm{~m}^{-/-}$ mice. ${ }^{68}$ The NKT cells in the $\beta 2 \mathrm{~m}^{-1-}$ mice do not respond to $\alpha$-GalCer, and therefore are Type II NKT cells. It can be noted that the NKT cell population in $\beta 2 \mathrm{~m}^{-/-}$mice is likely to be distinct from the Type II NKT cell population present in J $\alpha 18^{-/-}$ mice, which do not induce AHR, presumably because of the NKT cells that develop in the presence of the $\beta 2 \mathrm{~m}$-independent form of CD1d in $\beta 2 \mathrm{~m}^{-1-}$ mice may be distinct from those that develop in J $\alpha 18^{-/-}$mice. These studies, nevertheless, strongly suggest that the development of AHR in the $\beta 2 \mathrm{~m}^{-/-}$mice is mediated by CD1d-restricted NKT cells. ${ }^{68}$

A second situation in which AHR might appear to develop in the absence of iNKT cells involves T-bet-deficient mice, which were also believed not to have iNKT cells, but which developed AHR spontaneously. ${ }^{69}$ T-bet is a member of the T-box family of transcription factors that is expressed in Th1, but not in Th2 cells..$^{70,71}$ T-bet $^{-1-}$ mice have a significant defect in the maturation of iNKT cells, and therefore have a great reduction in peripheral iNKT cells, particularly in the liver. ${ }^{72}$ However, T-bet $^{-1-}$ mice have a significant number of iNKT cells in the spleen and lungs that produce primarily IL-4 and IL-13 and only minimal amounts of IFN- $\gamma .{ }^{73}$ Moreover, treatment of these mice with a blocking anti-CD1d mAb abolished spontaneous AHR as well as OVA-induced AHR, indicating that AHR in T-bet ${ }^{-1-}$ mice also required iNKT cells. ${ }^{73}$ Although there may be situations in which AHR can develop in the absence of iNKT cells (e.g., induced by the administration of recombinant IL-13), these studies together indicate that iNKT cells are indeed required for the development of AHR in most murine models of asthma.

\section{INKT CELLS IN HUMAN ASTHMA}

On the basis of the compelling studies of iNKT cells in mouse models of asthma, iNKT cells have been proposed to have an important role in human asthma. At least 13 studies have examined the number of iNKT cells in bronchoalveolar (BAL) fluid, endobronchial biopsies, and sputum samples from patients with asthma. Most of these studies (nine) concluded that iNKT cells were present in the lung of patients with asthma or chronic obstructive pulmonary disease, ${ }^{60,74-81}$ although four of the studies did not find a significant number of iNKT in samples from patients with asthma $^{82-85}$ (Table 2). These discrepancies have generated some controversy regarding the importance of iNKT cells in asthma. It should be noted that the techniques for identifying iNKT cells were quite varying in these 13 studies, and not all of the studies used $\alpha$-GalCer-loaded CD1d tetramer, anti-invariant NKT TCR $(6 \mathrm{~B} 11 \mathrm{Ab})$ or the combination of anti-V $\alpha 24 / \mathrm{V} \beta 11$, which are the best method for identifying iNKT cells. Moreover, a number of studies used sputum samples rather than BAL fluid samples, which may give variable results, as the cells in sputum samples may not all come from the lower airway.
However, in the most recent study of iNKT cells in human asthma, patients with a very broad range of asthma severity and symptom control, as well as non-asthmatic controls, were examined, using $\alpha$-GalCer-loaded CD1d tetramers with appropriate unloaded CD1d tetramer as a control to identify iNKT cells, along with stringent flow cytometry gating criteria. ${ }^{81} \mathrm{In}$ this study, patients with severe, poorly controlled asthma had a significant increase in the number of BAL fluid iNKT cells, compared with that in non-asthmatic controls. In addition, most, but not all, patients with well-controlled asthma had an increase in the number of BAL fluid iNKT cells compared with that in non-asthmatic controls. The specific number of iNKT cells present in the BAL fluid was quite varied (from $<1 \%$ up to $60 \%$ of the T cells), but patients with severe asthma appeared to more consistently have an increase in iNKT cells than those with well-controlled asthma, suggesting that asthma severity and symptom control might be loosely related to the number of pulmonary iNKT cells. ${ }^{81}$

All together, the data indicate that some but not all asthma patients have increased numbers of pulmonary iNKT cells, whereas normal individuals have very low or undetectable numbers of iNKT cells $(<1 \%$ of $\mathrm{T}$ cells). In addition, there is a great variability in the specific numbers of iNKT cells in patients with asthma, which might be explained by differences in the clinical character of patient populations studied, tissues used to analyze, and techniques used to identify the iNKT cells. Furthermore, iNKT cells are known to downregulate their TCRs when activated, rendering them undetectable using the tetramer analysis for period of at least several days. Overall, the studies in humans are consistent with those in mice, where the number of iNKT cells in BAL fluid fluctuates rapidly and dynamically, ranging from $1 \%$ of lung lymphocytes in naive mice to $14 \%$ after allergen challenge, ${ }^{73}$ suggesting that the number of iNKT cells in the lungs may change over time with acute exacerbations or as asthma symptoms improve. The variability in the number of iNKT cells suggests that the absence of iNKT cells in the lungs of some patients with asthma is not an indication that iNKT cells are not important in asthma, particularly because even small numbers of airway iNKT cells when activated can induce significant AHR. Rather the small number of iNKT cells present in some patients suggests that iNKT cells could have very potent activity. Therefore, functional studies of iNKT cells, as carried out in mice, rather than enumeration studies of iNKT in BAL fluid would be the best way to provide more convincing data regarding the importance of iNKT cells in asthma.

\section{FUNCTIONAL IN VIVO STUDIES OF PULMONARY INKT CELLS IN PRIMATES}

Unfortunately, functional in vivo studies of iNKT cells are difficult to carry out in humans for safety and ethical reasons. Therefore, functional studies have been limited to in vitro studies, which have shown that BAL fluid cells from patients with asthma respond in vitro to $\alpha$-GalCer (therefore iNKT cells are present in the lungs). ${ }^{74}$ Other investigators have shown that $\mathrm{CD} 4^{+}$iNKT cells from asthmatic patients show an increase in in vitro cytotoxic activity against regulatory 


\begin{tabular}{|c|c|c|c|c|c|c|}
\hline & \multirow[b]{2}{*}{ Disease $(n)^{1}$} & \multirow[b]{2}{*}{ Control $(n)^{1}$} & \multicolumn{2}{|c|}{ iNKT cell number } & \multirow{2}{*}{$\begin{array}{l}\text { Marker for } \\
\text { iNKT cell }\end{array}$} & \multirow[b]{2}{*}{ Tissue sample } \\
\hline & & & Disease & Control & & \\
\hline Akbari $^{74}$ & $\begin{array}{l}\text { Moderate-severe } \\
\text { asthma (14) }\end{array}$ & $\begin{array}{l}\text { Healthy (6) } \\
\text { Sarcoidosis (5) }\end{array}$ & $\begin{array}{l}58-68 \% \text { of } \mathrm{CD}^{+}+ \\
\mathrm{T} \text { cells }\end{array}$ & $\begin{array}{l}0.9 \% \text { of } \mathrm{CD}^{+} \\
\text {T cells (healthy) } \\
1.38 \% \text { of } \mathrm{CD}^{+} \\
\text {T cells (sarcoid) }\end{array}$ & $\begin{array}{l}\text { Tetramer } \\
6 \mathrm{~B} 11^{3}\end{array}$ & BAL \\
\hline Pham-thi ${ }^{76}$ & $\begin{array}{l}\text { Severe asthma } \\
\text { (15) }\end{array}$ & $\begin{array}{l}\text { Healthy (10) } \\
\text { Infection (12) }\end{array}$ & $\begin{array}{l}0.44 \pm 0.09 \% \text { of } \mathrm{CD}^{+} \\
\text {T cells }\end{array}$ & $\begin{array}{l}0.12 \pm 0.03 \% \text { of } \\
\text { CD } 3^{+} \mathrm{T} \text { cells } \\
\text { (healthy) } \\
0.142 \pm 0.05 \% \\
\text { of } \mathrm{CD} 3^{+} \mathrm{T} \text { cells } \\
\text { (infection) }\end{array}$ & Tetramer & BAL \\
\hline $\mathrm{Kim}^{60}$ & COPD (5) & Non-COPD (5) & 450 cells per $\mathrm{mm}^{3}$ & $\begin{array}{l}100 \text { cells } \\
\text { per } \mathrm{mm}^{3}\end{array}$ & Va24 & Lung tissue \\
\hline Yamamoto $^{78}$ & Asthma/sinusitis & Non-asthma & Increase & Undetectable & $\begin{array}{l}\text { RT PCR } \\
\text { V } \alpha 24 / J \alpha 18\end{array}$ & Nasal polyp \\
\hline Russano ${ }^{79}$ & Asthma & ND & $\begin{array}{l}\text { Upto } 5-10 \% \text { of } \mathrm{CD} 4^{+} \\
\text {T cells }\end{array}$ & ND & $?$ & BAL \\
\hline Fujiki 80 & Mild asthma (9) & ND & $\begin{array}{l}26.4 \pm 2.9 \% \text { of } \mathrm{CD}^{+} \\
\mathrm{T} \text { cells }\end{array}$ & ND & $6 \mathrm{~B} 11$ & Sputum \\
\hline Matangkasombut 81 & $\begin{array}{l}\text { Severe (5) } \\
\text { Well controlled (8) }\end{array}$ & Non-asthma (5) & $\begin{array}{l}\text { 1.3-63\% of } \mathrm{CD}^{+}{ }^{+} \\
\text {T cells (severe) } \\
0-8 \% \text { of CD }{ }^{+} \mathrm{T} \\
\text { cells (well controlled) }\end{array}$ & $\begin{array}{l}0-0.2 \% \text { of } \\
\text { CD3 }+ \text { T cells }\end{array}$ & Tetramer & BAL \\
\hline Vijayanand 83 & $\begin{array}{l}\text { Mild-moderate } \\
\text { asthma(16) } \\
\text { COPD(10) }\end{array}$ & Healthy (12) & $\begin{array}{l}0-2.7 \% \text { of } \mathrm{CD}^{+} \\
\mathrm{T} \text { cells (asthma) } \\
0-0.9 \% \text { of CD3 }{ }^{+} \\
\text {T cells (COPD) }\end{array}$ & $\begin{array}{l}0-0.6 \% \text { of } \\
\text { CD3 }+ \text { T cells }\end{array}$ & $\begin{array}{l}\text { Tetramer, } \\
6 \mathrm{~B} 11 \\
\text { V } \alpha 24 / \mathrm{V} \beta 11\end{array}$ & $\begin{array}{l}\text { BAL } \\
\text { Lung biopsy } \\
\text { Sputum }\end{array}$ \\
\hline Thomas $^{84}$ & Mild asthma (5) & ND & $\begin{array}{l}0.4-2.1 \% \text { of lym- } \\
\text { phocytes }\end{array}$ & ND & $\begin{array}{l}6 \mathrm{~B} 11 \\
\mathrm{~V} \alpha 24\end{array}$ & BAL \\
\hline Bratke $^{85}$ & Mild asthma (6) & ND & $<1 \%$ of $\mathrm{T}$ cells & ND & $6 \mathrm{~B} 11$ & BAL \\
\hline
\end{tabular}

BAL, bronchoalveolar lavage fluid; COPD, chronic obstructive pulmonary disease; $\alpha$-GalCer, $\alpha$-galactosylceramide; iNKT, invariant natural killer T cells; ND, not done.

${ }^{1}$ Number of subjects.

${ }^{2} \alpha$-GalCer-loaded CD1d tetramer.

${ }^{3}$ Anti-invariant NKT cell receptor (clone 6B11).

T cells. ${ }^{86}$ As in vivo studies in humans are difficult to be carried out, as an alternative, one can examine the in vivo function of pulmonary iNKT cells in non-human primates, for example, in cynomolgus monkeys. As in mice, direct and specific activation in monkeys of pulmonary iNKT cells with $\alpha$-GalCer resulted in the development of significant AHR. ${ }^{87}$ These results suggested that even the few iNKT cells (0.3$0.6 \%$ of $\mathrm{T}$ cells) present in the normal lung, when directly activated, induce the development of AHR. Thus, similar to mast cells or dendritic cells (DCs), iNKT cells have potent activity, which cannot be assessed simply by counting their numbers in the lung. Furthermore, because non-human primates are closely related to humans in terms of their genome, respiratory physiology, and immunological responses, ${ }^{88}$ these results predict that challenge of humans with glycolipids that directly activate iNKT cells would result in a similar development of AHR. Therefore, these studies provide strong evidence that iNKT cells likely have an 
important role in human asthma, and suggest that additional functional studies of iNKT cells are warranted in humans. These studies should include examination of the precise factors that control the number and mechanisms of the recruitment of iNKT cells in the lungs, beyond the observations that CCR4 and CCR9 are important in the recruitment of iNKT cells to the lung, ${ }^{75,89}$ which should greatly help us understand their function in asthma.

\section{LIPID ANTIGENS THAT ACTIVATE PULMONARY INKT CELLS}

A major question in iNKT cell biology involves the identification of lipid antigens that can activate iNKT cells. In allergen-induced and ozone-induced AHR, it is believed that endogenous glycolipids become expressed or modified in the inflammatory environment induced by Th 2 cells and by ozone, respectively, which then activate different subsets of iNKT cells, which in turn induce AHR. The known endogenous lipids include isoglobotrihexosylceramide, a lysosomal glycosphingolipid which can stimulate both mouse and human iNKT cells, ${ }^{90}$ cellular phospholipids, that is, phosphatidylcholine, ${ }^{91}$ phosphatidylinositol, phosphatidylglycerol, and phosphatidylethanolamine. ${ }^{92,93}$ In addition, endogenous lipids in other specific tissues such as disialoganglioside GD3 from tumor cells activates iNKT cells, ${ }^{94}$ and sulfatide from myelin activates type II NKT cells. ${ }^{95}$ Whether any of these lipid antigens are involved in activating pulmonary iNKT cells, or whether the iNKT cells are activated through an indirect pathway, for example, by cytokines, is not known as yet, and will require further investigation.

Pulmonary iNKT cells are believed to be activated not only by endogenous lipids but also by exogenous lipids derived from microorganisms or plants. Indeed, a single intranasal administration of an exogenous glycolipid, $\alpha$-GalCer, to naive mice directly activates iNKT cells and results in the rapid development of severe AHR, which peaks at $24 \mathrm{~h}$, and is associated with airway inflammation and characterized by neutrophils, eosinophils, and lymphocytes. ${ }^{96}$ This response was dependent on iNKT cells, but was independent of conventional CD4 ${ }^{+}$ T cells. ${ }^{96}$ A similar response was generated with glycolipids structurally resembling $\alpha$-GalCer, isolated from a Gramnegative, lipopolysaccharide-negative $\alpha$-proteobacteria Sphingomonas. ${ }^{96-98}$ Although Sphingomonas is not known as pulmonary pathogen, this study strongly suggests that lipids from other pathogens may directly activate pulmonary iNKT cells, resulting in the development of AHR and asthma.

The list of microorganisms that produce lipids that activate iNKT cells is rapidly growing. ${ }^{99}$ For example, diacylglycerol antigens from the causative agent of Lyme disease, Borrelia burgdorferi glycolipid II, were shown to stimulate iNKT cells. ${ }^{100}$ Furthermore, mycobacterium cell wall possesses phosphatidylinositol mannoside, which binds to CD1d and activates mouse and human iNKT cells. ${ }^{101,102}$ In addition, lipophosphoglycan and glycoinositolphospholipids purified from Leishmania donovani activate iNKT cells. ${ }^{103}$ Other organisms, such as Salmonella typhimurium, Listeria monocytogenes, Staphylococcus aureus, Escherichia coli, and cytomegalovirus, may also activate iNKT

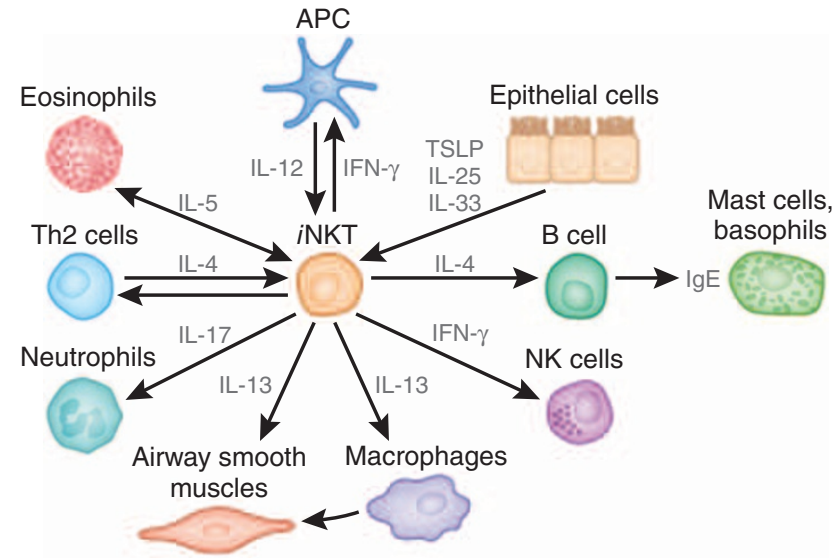

Figure 1 Invariant natural killer T cells (iNKT) cell function in airway hyperreactivity (AHR). iNKT cells secrete various cytokines, including Th2 cytokines, which have direct effects on hematopoietic cells, airway smooth muscle cells, and goblet cells. Alternatively, iNKT cells could regulate other cell types that are known to be involved in asthma pathogenesis, e.g., neutrophils and alveolar macrophages.

cells, but in an indirect manner by stimulating DC production of cytokines such as IL-12, which then activate iNKT cells. ${ }^{104-108}$ Finally, glycolipids expressed by plant pollens, such as cypress tree pollen, may directly activate iNKT cells when they are inhaled. ${ }^{109}$

\section{INKT CELL FUNCTION IN AHR}

The mechanisms by which iNKT cells function in inducing AHR is unclear (Figure 1). Although AHR is a complex response, involving multiple cell types, including immune cells and structural cells, such as airway smooth muscle and airway epithelial cells, the role of iNKT cells in causing AHR is likely related to the cytokines that they produce. iNKT cells rapidly secrete a large amount of various cytokines, including Th2 cytokines, which are known to enhance allergic inflammation and AHR, by having direct effects on hematopoietic cells and on airway smooth muscle cells and goblet cells. ${ }^{9}$ How iNKT cells differ from Th2 cells, or whether iNKT cells and Th2 cells have overlapping functions is not fully known. Alternatively, iNKT cells could regulate other cell types that are known to be involved in non-allergic asthma pathogenesis. For example, the production of IL-17 by some iNKT cell subsets could recruit neutrophils to the airways, ${ }^{20,22,53-56}$ or iNKT cells could activate alveolar macrophages to produce IL-13, which then induce chronic lung disease. ${ }^{60}$ Furthermore, iNKT cells from asthmatic patients have been shown be cytotoxic to regulatory $\mathrm{T}$ cells, which normally suppress airway inflammation, ${ }^{86}$ suggesting another potential role of iNKT cells in asthma. Finally, iNKT cells may provide unique effects required for the development of AHR, and these effects may be induced by other cytokines, as discussed below.

\section{NOVEL CYTOKINES THAT ACTIVATE INKT CELLS}

There are a number of novel cytokines that have been shown recently to affect the development of asthma and AHR. Not surprisingly, many of these agents affect iNKT cells, consistent with the idea that iNKT cells have a central role in AHR. 
For example, IL-25, which is a member of the IL-17 family cytokines (also known as IL-17E), has been detected in the lungs of patients with asthma, ${ }^{110}$ and greatly enhances Th2 response. ${ }^{111}$ In a model of allergic asthma, IL-25 was expressed by lung epithelial cells, and induced allergic airway inflammation as well as AHR. ${ }^{112-114}$ Conversely, blocking IL-25 eliminated Th2 response and AHR. ${ }^{115}$ Moreover, IL-17RB, which serves as a receptor for IL-25 and is expressed on non-B/non- $\mathrm{T}$ (NBNT) c-kit ${ }^{+} \mathrm{FcERI}^{-}$cells in mesenteric lymph nodes, is also expressed by a subset of iNKT cells in BALB/c (but not C57B/6) mice. ${ }^{116,117}$ It is important that the IL-17RB-expressing iNKT cells greatly enhanced AHR induced by IL-25 and suboptimal doses of protein allergen, because this response occurred only in wild-type but not in $\mathrm{J} \alpha 18^{-/-}$mice. ${ }^{116}$ Furthermore, transferring IL-17RB ${ }^{+}$but not IL-17RB ${ }^{-}$iNKT cells into $\mathrm{J} \alpha 18^{-/-}$mice restored allergen-induced AHR. ${ }^{117}$ The novel IL-17RB ${ }^{+}$iNKT cell subset expressed CD4, preferentially produced IL-13 and IL-4, and also expressed CCR $4,{ }^{116}$ which is known to mediate the localization of iNKT cells into the airways. ${ }^{89}$ This study suggests that $\mathrm{CD} 4{ }^{+} \mathrm{IL}-17 \mathrm{RB}^{+}$iNKT cells have a critical role in the pathogenesis of asthma induced by IL- 25 .

Another cytokine that affects iNKT cells is IL-33, a member of the IL- 1 family and a ligand for ST2, a receptor on Th2 cells and some iNKT cells. ${ }^{18,119} \mathrm{IL}-33$ is produced by epithelial cells and DCs, and the administration of IL-33 into the lungs of mice induced AHR and goblet cell hyperplasia. The precise mechanism of this AHR response in not totally clear, particularly because this response could occur in the absence of adaptive immune cells (e.g., in RAG-2 $2^{-/}$mice), but may involve the direct activation of mast cells and basophils. ${ }^{120-122}$

Thymic stromal lymphopoietin (TSLP) is another novel cytokine that has been suggested to be a master switch for allergic inflammation at the epithelial-DC interface. ${ }^{123}$ It is secreted primarily by epithelial cells, and activates DCs, which preferentially induce Th2 cell differentiation in T cells. ${ }^{124,125}$ Nagata et al. ${ }^{126}$ showed that iNKT cells also express the TSLP receptor and respond to TSLP by preferentially increasing IL- 13 but not IFN- $\gamma$ or IL- 4 production. Moreover, TSLP transgenic mice developed pulmonary eosinophilia, increased IgE production, and allergen-induced AHR, but only when iNKT cells were present. ${ }^{126}$ Thus, TSLP transgenic mice that lacked iNKT cells failed to develop AHR, although they still developed pulmonary eosinophilia and increased IgE, showing that TSLP promotes the development of AHR through the activation of iNKT cells.

Other cytokines involved in iNKT cell activation, include TNFSF15, a cytokine produced by DCs, which co-stimulates effector T-cell development by binding to its receptor, TNFR25 (DR3, TRAMP, LARD, WSL-1). ${ }^{127}$ TNFSF15 stimulates IL-13 production in iNKT cells, and this pathway appears to be critical for allergic lung inflammation and AHR. ${ }^{28}$ Similarly, the inducible co-stimulator (ICOS)/ICOS ligand pathway is required for iNKT cell survival and the induction of AHR. ${ }^{129}$ Finally, IL-18 stimulates IgE production, in part, by activating iNKT cells, ${ }^{130}$ and may contribute to the development of AHR and airway inflammation. ${ }^{131}$

\section{TARGETING INKT CELLS FOR ASTHMA THERAPY}

On account of its crucial roles in different forms of asthma, iNKT cells serve as an attractive target for asthma therapy. Although iNKT cells have important antimicrobial and antitumor effects, therapies that specifically target iNKT cells are likely to be much less "immunosuppressive" than therapies, for example, with corticosteroids, which have very broad immunosuppressive effects and which remain the most common therapy for asthma. Therapies targeting iNKT cells could involve in the direct elimination of iNKT cells, paralyzing iNKT cell function, preventing their activation by blocking CD1d, or altering iNKT cell function by reducing Th2 cytokine production. For example, Hachem et al. ${ }^{132}$ and Matsuda et al. ${ }^{133}$ inhibited OVA-induced AHR by administration of $\alpha$-GalCer systemically. The authors found that the inhibition of AHR was dependent on IFN- $\gamma$ production ${ }^{132,133}$ and that the effect was transferable, ${ }^{133}$ suggesting that IFN- $\gamma$ inhibitory cells were induced. However, $\alpha$-GalCer when given directly into the lungs or when given continuously during OVA sensitization can induce AHR and airway inflammation, ${ }^{96,134}$ suggesting that the route and timing of $\alpha$-GalCer administration could dictate the response ${ }^{135}$ and that other glycolipids, perhaps with a reduced capacity to induce Th2 cytokine production, may be more effective.

Lessons learned from active investigation on harnessing iNKT cells for the treatment and prevention of tumor, autoimmune diseases, and for vaccine development could help us better develop therapy for asthma. Most studies in cancer field used $\alpha$-GalCer or DCs loaded with $\alpha$-GalCer, which showed promising efficacy in animal models ${ }^{136-140}$ and found to be safe in phase I clinical trail in humans. ${ }^{141-143}$ Moreover, a $\mathrm{C}$-glycoside analog of $\alpha$-GalCer has been shown to induce iNKT cells to produce skewed Th1 cytokines, ${ }^{144}$ and was shown to be more potent than $\alpha$-GalCer in both antitumor and antimalarial efficacy. ${ }^{145}$ In autoimmune disease field, another analog of $\alpha$-GalCer with a truncation of sphingosine chain, $\mathrm{OCH}$ compound, has been shown to induce skewed Th2 response and to protect mice against a Th1 disease, experimental autoimmune encephalitis (murine model for multiple sclerosis), and collageninduced arthritis. ${ }^{146,147}$ These studies suggest that customized glycolipids might be effective in altering the functions of iNKT cells, reducing Th2 cytokine production, and enhancing Th1 or regulatory iNKT cell function. Furthermore, if our hypothesis regarding exogenous lipid antigen activation of iNKT cells is correct, then in addition to regulating iNKT cells, themselves, the environmental control of "lipid allergens" might help certain asthmatic patients in a similar way that environmental control of protein allergens do.

\section{CONCLUSION AND FUTURE DIRECTIONS}

Our understanding of the function of iNKT cells in asthma has progressed markedly over the past 6 years since the role of iNKT cells in asthma was first proposed. Although murine models of asthma provide strong evidence that different subsets of iNKT cells are required in different forms of asthma, the significance of this observation need to be confirmed by further study in humans. How various subsets of iNKT cells are regulated, how 
pulmonary iNKT cells are activated and exert their functions, and how can we manipulate them in order to prevent and treat asthma remain to be elucidated.

\section{DISCLOSURE}

Corresponding author is a consultant for Innate Immune Inc.

() 2009 Society for Mucosal Immunology

\section{REFERENCES}

1. Busse, W.W. \& Lemanske Jr, R.F. Asthma. N. Engl. J. Med. 344, 350-362 (2001).

2. Mannino, D.M., Homa, D.M., Akinbami, L.J., Moorman, J.E., Gwynn, C. \& Redd, S.C. Surveillance for asthma-United States, 1980-1999. MMWR Surveill. Summ. 51, 1-13 (2002).

3. Umetsu, D.T., Mclntire, J.J., Akbari, O., Macaubas, C. \& DeKruyff, R.H. Asthma: an epidemic of dysregulated immunity. Nat. Immunol. 3, 715-720 (2002).

4. von Mutius, E. Gene-environment interactions in asthma. J. Allergy Clin. Immunol. 123, 3-11; quiz 2-3 (2009).

5. Vercelli, D. Discovering susceptibility genes for asthma and allergy. Nat. Rev. Immunol. 8, 169-182 (2008).

6. Anderson, G.P. Endotyping asthma: new insights into key pathogenic mechanisms in a complex, heterogeneous disease. Lancet $\mathbf{3 7 2}$, 1107-1119 (2008)

7. National Heart Lung and Blood Institute. Title: Expert Panel Report 3 (EPR3): Guidelines for the Diagnosis and Management of Asthma. 2007 Contract no.: Document no item no. 08-4051.

8. Burrows, B., Martinez, F.D., Halonen, M., Barbee, R.A. \& Cline, M.G. Association of asthma with serum IgE levels and skin-test reactivity to allergens. N. Engl. J. Med. 320, 271-277 (1989).

9. Wills-Karp, M. Immunologic basis of antigen-induced airway hyperresponsiveness. Annu. Rev. Immunol. 17, 255-281 (1999).

10. Robinson, D.S. et al. Predominant TH2-like bronchoalveolar T-lymphocyte population in atopic asthma. N. Engl. J. Med. 326, 298-304 (1992).

11. Wills-Karp, M. \& Ewart, S.L. The genetics of allergen-induced airway hyperresponsiveness in mice. Am. J. Respir. Crit. Care Med. 156 (4 Part 2), S89-S96 (1997).

12. Martinez, F.D. et al. Asthma and wheezing in the first six years of life. $N$. Engl. J. Med. 332, 133-138 (1995).

13. Gavett, S.H., Chen, X., Finkelman, F. \& Wills-Karp, M. Depletion of murine CD4+ T lymphocytes prevents antigen-induced airway hyperreactivity and pulmonary eosinophilia. Am. J. Respir. Cell Mol. Biol. 10, 587-593 (1994).

14. Cohn, L., Elias, J.A. \& Chupp, G.L. Asthma: mechanisms of disease persistence and progression. Annu. Rev. Immunol. 22, 789-815 (2004).

15. Wenzel, S., Wilbraham, D., Fuller, R., Getz, E.B. \& Longphre, M. Effect of an interleukin- 4 variant on late phase asthmatic response to allergen challenge in asthmatic patients: results of two phase $2 a$ studies. Lancet 370, 1422-1431 (2007).

16. Leckie, M.J. et al. Effects of an interleukin- 5 blocking monoclonal antibody on eosinophils, airway hyper-responsiveness, and the late asthmatic response. Lancet 356, 2144-2148 (2000).

17. Corren, J. Allergic rhinitis and asthma: how important is the link? J. Allergy Clin. Immunol. 99, S781-S786 (1997).

18. Cho, S.H., Stanciu, L.A., Holgate, S.T. \& Johnston, S.L. Increased interleukin-4, interleukin-5, and interferon-gamma in airway CD4+ and CD8+ T cells in atopic asthma. Am. J. Respir. Crit. Care Med. 171, 224-230 (2005).

19. Nakao, F. et al. Association of IFN-gamma and IFN regulatory factor 1 polymorphisms with childhood atopic asthma. J. Allergy Clin. Immunol. 107, 499-504 (2001).

20. Bullens, D.M. et al. IL-17 mRNA in sputum of asthmatic patients: linking T cell driven inflammation and granulocytic influx? Respir. Res. 7, 135 (2006).

21. Oboki, K., Ohno, T., Saito, H. \& Nakae, S. Th17 and allergy. Allergol. Int. 57, 121-134 (2008).

22. Pichavant, M. et al. Ozone exposure in a mouse model induces airway hyperreactivity that requires the presence of natural killer T cells and IL-17. J. Exp. Med. 205, 385-393 (2008).
23. Haldar, P. \& Pavord, I.D. Noneosinophilic asthma: a distinct clinical and pathologic phenotype. J. Allergy Clin. Immunol. 119, 1043-1052; quiz 1053-1054 (2007).

24. Kay, A.B. Inflammatory cells in bronchial asthma. J. Asthma 26, 335-344 (1989).

25. Simpson, J.L., Grissell, T.V., Douwes, J., Scott, R.J., Boyle, M.J. \& Gibson, P.G. Innate immune activation in neutrophilic asthma and bronchiectasis. Thorax 62, 211-218 (2007).

26. Chanez, P. et al. Severe asthma in adults: what are the important questions? J. Allergy Clin. Immunol. 119, 1337-1348 (2007).

27. Green, R.H., Brightling, C.E., Woltmann, G., Parker, D., Wardlaw, A.J. \& Pavord, I.D. Analysis of induced sputum in adults with asthma: identification of subgroup with isolated sputum neutrophilia and poor response to inhaled corticosteroids. Thorax 57, 875-879 (2002).

28. Looringh van Beeck, F.A. et al. Functional CD1d and/or NKT cell invariant chain transcript in horse, pig, African elephant and guinea pig, but not in ruminants. Mol. Immunol. 46, 1424-1431 (2009).

29. Van Rhijn, I. et al. The bovine CD1 family contains group $1 \mathrm{CD} 1$ proteins, but no functional CD1d. J. Immunol. 176, 4888-4893 (2006).

30. Kawano, T. et al. CD1d-restricted and TCR-mediated activation of valpha14 NKT cells by glycosylceramides. Science $278,1626-1629$ (1997).

31. Spada, F.M., Koezuka, Y. \& Porcelli, S.A. CD1d-restricted recognition of synthetic glycolipid antigens by human natural killer T cells. J. Exp. Med. 188, 1529-1534 (1998).

32. Scott-Browne, J.P. et al. Germline-encoded recognition of diverse glycolipids by natural killer T cells. Nat. Immunol. 8, 1105-1113 (2007).

33. Bendelac, A., Savage, P.B. \& Teyton, L. The biology of NKT cells. Annu. Rev. Immunol. 25, 297-336 (2007).

34. Taniguchi, M. \& Nakayama, T. Recognition and function of Valpha14 NKT cells. Semin. Immunol. 12, 543-550 (2000).

35. Kawano, T. et al. Antitumor cytotoxicity mediated by ligand-activated human V alpha24 NKT cells. Cancer Res. 59, 5102-5105 (1999).

36. Metelitsa, L.S. et al. Human NKT cells mediate antitumor cytotoxicity directly by recognizing target cell CD1d with bound ligand or indirectly by producing IL-2 to activate NK cells. J. Immunol. 167, 3114-3122 (2001).

37. Kinjo, Y. \& Kronenberg, M. Valpha14i NKT cells are innate lymphocytes that participate in the immune response to diverse microbes. J. Clin. Immunol. 25, 522-533 (2005).

38. Skold, M. \& Behar, S.M. Role of CD1d-restricted NKT cells in microbial immunity. Infect. Immun. 71, 5447-5455 (2003).

39. Terabe, M. \& Berzofsky, J.A. The role of NKT cells in tumor immunity. Adv. Cancer Res. 101, 277-348 (2008).

40. Ronchi, F. \& Falcone, M. Immune regulation by invariant NKT cells in autoimmunity. Front. Biosci. 13, 4827-4837 (2008).

41. Seino, K.I. et al. Requirement for natural killer T (NKT) cells in the induction of allograft tolerance. Proc. Natl. Acad. Sci. USA 98, 2577-2581 (2001).

42. Tupin, E. et al. CD1d-dependent activation of NKT cells aggravates atherosclerosis. J. Exp. Med. 199, 417-422 (2004).

43. Umetsu, D.T. \& DeKruyff, R.H. A role for natural killer T cells in asthma. Nat. Rev. Immunol. 6, 953-958 (2006).

44. Akbari, O. et al. Essential role of NKT cells producing IL-4 and IL-13 in the development of allergen-induced airway hyperreactivity. Nat. Med. 9, 582-588 (2003).

45. Lisbonne, M. et al. Cutting edge: invariant $V$ alpha 14 NKT cells are required for allergen-induced airway inflammation and hyperreactivity in an experimental asthma model. J. Immunol. 171, 1637-1641 (2003).

46. Das, J. et al. Natural killer T cells and CD8+ T cells are dispensable for $T$ cell-dependent allergic airway inflammation. Nat. Med. 12, 1345-1346; author reply 7 (2006).

47. Korsgren, M. et al. Natural killer cells determine development of allergeninduced eosinophilic airway inflammation in mice. J. Exp. Med. 189, 553-562 (1999).

48. Bilenki, L., Yang, J., Fan, Y., Wang, S. \& Yang, X. Natural killer T cells contribute to airway eosinophilic inflammation induced by ragweed through enhanced IL-4 and eotaxin production. Eur. J. Immunol. 34, 345-354 (2004).

49. Smiley, S.T., Kaplan, M.H. \& Grusby, M.J. Immunoglobulin E production in the absence of interleukin-4-secreting CD1-dependent cells. Science 275, 977-979 (1997). 
50. Aris, R.M., Christian, D., Hearne, P.Q., Kerr, K., Finkbeiner, W.E. \& Balmes, JR. Ozone-induced airway inflammation in human subjects as determined by airway lavage and biopsy. Am. Rev. Respir. Dis. 148, 1363-1372 (1993).

51. Gent, J.F. et al. Association of low-level ozone and fine particles with respiratory symptoms in children with asthma. JAMA 290, 1859-1867 (2003).

52. Rachitskaya, A.V. et al. Cutting edge: NKT cells constitutively express IL-23 receptor and RORgammat and rapidly produce IL-17 upon receptor ligation in an IL-6-independent fashion. J. Immunol. 180, 5167-5171 (2008).

53. Michel, M.L. et al. Identification of an IL-17-producing NK1.1(neg) iNKT cell population involved in airway neutrophilia. J. Exp. Med. 204, 995-1001 (2007).

54. Lee, K.A. et al. A distinct subset of natural killer T cells produces IL-17, contributing to airway infiltration of neutrophils but not to airway hyperreactivity. Cell Immunol. 251, 50-55 (2008).

55. Coquet, J.M. et al. Diverse cytokine production by NKT cell subsets and identification of an IL-17-producing CD4-NK1.1- NKT cell population. Proc. Natl. Acad. Sci. USA 105, 11287-11292 (2008).

56. Goto, M. et al. Murine NKT cells produce Th17 cytokine interleukin-22. Cell Immunol. 254, 81-84 (2009).

57. Gern, J.E. \& Busse, W.W. The role of viral infections in the natural history of asthma. J. Allergy Clin. Immunol. 106, 201-212 (2000).

58. Sigurs, N. et al. Severe respiratory syncytial virus bronchiolitis in infancy and asthma and allergy at age 13. Am. J. Respir. Crit. Care Med. 171, 137-141 (2005).

59. Hamelin, M.E., Prince, G.A., Gomez, A.M., Kinkead, R. \& Boivin, G. Human metapneumovirus infection induces long-term pulmonary inflammation associated with airway obstruction and hyperresponsiveness in mice. J. Infect. Dis. 193, 1634-1642 (2006)

60. Kim, E.Y. et al. Persistent activation of an innate immune response translates respiratory viral infection into chronic lung disease. Nat. Med. 14, 633-640 (2008).

61. Brown, D.R. et al. Beta 2-microglobulin-dependent NK1.1+ T cells are not essential for Thelper cell 2 immune responses. J. Exp. Med. 184, 1295-1304 (1996).

62. Zhang, Y., Rogers, K.H. \& Lewis, D.B. Beta 2-microglobulin-dependent T cells are dispensable for allergen-induced Thelper 2 responses. J. Exp. Med. 184, 1507-1512 (1996).

63. Amano, M. et al. CD1 expression defines subsets of follicular and marginal zone B cells in the spleen: beta 2-microglobulin-dependent and independent forms. J. Immunol. 161, 1710-1717 (1998).

64. Balk, S.P. et al. Beta 2-microglobulin-independent MHC class lb molecule expressed by human intestinal epithelium. Science 265, 259-262 (1994).

65. Kim, H.S., Garcia, J., Exley, M., Johnson, K.W., Balk, S.P. \& Blumberg, R.S. Biochemical characterization of CD1d expression in the absence of beta2-microglobulin. J. Biol. Chem. 274, 9289-9295 (1999).

66. Paduraru, C. et al. An N-linked glycan modulates the interaction between the CD1d heavy chain and beta 2-microglobulin. J. Biol. Chem. 281, 40369-40378 (2006)

67. Maeda, M., Shadeo, A., MacFadyen, A.M. \& Takei, F. CD1dindependent NKT cells in beta 2-microglobulin-deficient mice have hybrid phenotype and function of NK and T cells. J. Immunol. 172, 6115-6122 (2004)

68. Koh, Y.I. et al. Activation of nonclassical CD1d-restricted NK T cells induces airway hyperreactivity in beta 2-microglobulin-deficient mice. J. Immunol. 181, 4560-4569 (2008).

69. Finotto, S. et al. Development of spontaneous airway changes consistent with human asthma in mice lacking T-bet. Science 295, 336-338 (2002).

70. Szabo, S.J., Sullivan, B.M., Peng, S.L. \& Glimcher, L.H. Molecular mechanisms regulating Th1 immune responses. Annu. Rev. Immunol. 21, 713-758 (2003).

71. Szabo, S.J., Sullivan, B.M., Stemmann, C., Satoskar, A.R., Sleckman, B.P. \& Glimcher, L.H. Distinct effects of T-bet in TH1 lineage commitment and IFN-gamma production in CD4 and CD8 T cells. Science 295, 338-342 (2002).

72. Townsend, M.J. et al. T-bet regulates the terminal maturation and homeostasis of NK and Valpha14i NKT cells. Immunity 20, 477-494 (2004).

73. Kim, H.Y. et al. The development of airway hyperreactivity in T-betdeficient mice requires CD1d-restricted NKT cells. J. Immunol. 182, 3252-3261 (2009).
74. Akbari, O. et al. CD4+ invariant T-cell-receptor+ natural killer T cells in bronchial asthma. N. Engl. J. Med. 354, 1117-1129 (2006).

75. Sen, Y. et al. V alpha 24-invariant NKT cells from patients with allergic asthma express CCR9 at high frequency and induce Th2 bias of CD3+ T cells upon CD226 engagement. J. Immunol. 175, 4914-4926 (2005).

76. Pham-Thi, N., de Blic, J., Le Bourgeois, M., Dy, M., Scheinmann, P. \& Leite-de-Moraes, M.C. Enhanced frequency of immunoregulatory invariant natural killer T cells in the airways of children with asthma. J. Allergy Clin. Immunol. 117, 217-218 (2006).

77. Hamzaoui, A. et al. NKT cells in the induced sputum of severe asthmatics. Mediators Inflamm. 2006, 71214 (2006).

78. Yamamoto, H., Okamoto, Y., Horiguchi, S., Kunii, N., Yonekura, S. \& Nakayama, T. Detection of natural killer T cells in the sinus mucosa from asthmatics with chronic sinusitis. Allergy 62, 1451-1455 (2007).

79. Russano, A.M., Agea, E., Casciari, C., de Benedictis, F.M. \& Spinozzi, F. Complementary roles for lipid and protein allergens in triggering innate and adaptive immune systems. Allergy 63, 1428-1437 (2008).

80. Fujiki, R., Yokoyama, T., Watson, R., Gauvreau, G. \& O'Byrne, P. NKT cells in sputum and peripheral blood from subjects with allergen-induced late asthmatic responses. J. Resp. Crit. Care Med. 2007; ATS abstracts: A680 (2007).

81. Matangkasombut, P. et al. Natural killer T cells in the lungs of patients with asthma. J. Allergy Clin. Immunol. (2009).

82. Mutalithas, $\mathrm{K}$. et al. Bronchoalveolar lavage invariant natural killer T cells are not increased in asthma. J. Allergy Clin. Immunol. 119, 1274-1276 (2007).

83. Vijayanand, P. et al. Invariant natural killer T cells in asthma and chronic obstructive pulmonary disease. N. Engl. J. Med. 356, 1410-1422 (2007).

84. Thomas, S.Y., Lilly, C.M. \& Luster, A.D. Invariant natural killer T cells in bronchial asthma. N. Engl. J. Med. 354, 2613-2616; author reply: 2613-2616 (2006).

85. Bratke, K., Julius, P. \& Virchow, J.C. Invariant natural killer T cells in obstructive pulmonary diseases. N. Engl. J. Med. 357, 194; author reply: 194-145 (2007).

86. Nguyen, K.D., Vanichsarn, C. \& Nadeau, K.C. Increased cytotoxicity of CD4+ invariant NKT cells against CD4+CD25hiCD127lo/regulatory T cells in allergic asthma. Eur. J. Immunol. 38, 2034-2045 (2008).

87. Matangkasombut, P. et al. Direct activation of natural killer T cells induces airway hyperreactivity in nonhuman primates. J. Allergy Clin. Immunol. 121, 1287-1289 (2008).

88. Coffman, R.L. \& Hessel, E.M. Nonhuman primate models of asthma. J. Exp. Med. 201, 1875-1879 (2005).

89. Meyer, E.H. et al. iNKT cells require CCR4 to localize to the airways and to induce airway hyperreactivity. J. Immunol. 179, 4661-4671 (2007).

90. Zhou, D. et al. Lysosomal glycosphingolipid recognition by NKT cells. Science 306, 1786-1789 (2004).

91. Giabbai, B. et al. Crystal structure of mouse CD1d bound to the self ligand phosphatidylcholine: a molecular basis for NKT cell activation. J. Immunol. 175, 977-984 (2005).

92. Gumperz, J.E. et al. Murine CD1d-restricted T cell recognition of cellular lipids. Immunity 12, 211-221 (2000).

93. Rauch, J. et al. Structural features of the acyl chain determine selfphospholipid antigen recognition by a CD1d-restricted invariant NKT (iNKT) cell. J. Biol. Chem. 278, 47508-47515 (2003).

94. Wu, D.Y., Segal, N.H., Sidobre, S., Kronenberg, M. \& Chapman, P.B. Cross-presentation of disialoganglioside GD3 to natural killer T cells. J. Exp. Med. 198, 173-181 (2003).

95. Zajonc, D.M. et al. Structure and function of a potent agonist for the semi-invariant natural killer T cell receptor. Nat. Immunol. 6, 810-818 (2005).

96. Meyer, E.H. et al. Glycolipid activation of invariant T cell receptor+ NKT cells is sufficient to induce airway hyperreactivity independent of conventional CD4+ T cells. Proc. Natt. Acad. Sci. USA 103, 2782-2787 (2006).

97. Kinjo, Y. et al. Recognition of bacterial glycosphingolipids by natural killer T cells. Nature 434, 520-525 (2005).

98. Mattner, J. et al. Exogenous and endogenous glycolipid antigens activate NKT cells during microbial infections. Nature 434, 525-529 (2005).

99. Tsuji, M. Glycolipids and phospholipids as natural CD1d-binding NKT cell ligands. Cell. Mol. Life Sci. 63, 1889-1898 (2006).

100. Kinjo, Y. et al. Natural killer T cells recognize diacylglycerol antigens from pathogenic bacteria. Nat. Immunol. 7, 978-986 (2006). 
101. Fischer, K. et al. Mycobacterial phosphatidylinositol mannoside is a natural antigen for CD1d-restricted T cells. Proc. Natl. Acad. Sci. USA 101, 10685-10690 (2004).

102. Gilleron, M., Ronet, C., Mempel, M., Monsarrat, B., Gachelin, G. \& Puzo, G. Acylation state of the phosphatidylinositol mannosides from Mycobacterium bovis bacillus Calmette Guerin and ability to induce granuloma and recruit natural killer T cells. J. Biol. Chem. 276, 34896-34904 (2001).

103. Amprey, J.L. et al. A subset of liver NKT cells is activated during Leishmania donovani infection by CD1d-bound lipophosphoglycan. J. Exp. Med. 200, 895-904 (2004).

104. Brigl, M., Bry, L., Kent, S.C., Gumperz, J.E. \& Brenner, M.B. Mechanism of CD1d-restricted natural killer $T$ cell activation during microbial infection. Nat. Immunol. 4, 1230-1237 (2003).

105. Paget, C. et al. Activation of invariant NKT cells by toll-like receptor 9 stimulated dendritic cells requires type I interferon and charged glycosphingolipids. Immunity 27, 597-609 (2007).

106. Kim, S., Lalani, S., Parekh, V.V., Vincent, T.L., Wu, L. \& Van Kaer, L. Impact of bacteria on the phenotype, functions, and therapeutic activities of invariant NKT cells in mice. J. Clin. Invest. 118, 2301-2315 (2008).

107. Tyznik, A.J., Tupin, E., Nagarajan, N.A., Her, M.J., Benedict, C.A. \& Kronenberg, M. Cutting edge: the mechanism of invariant NKT cell responses to viral danger signals. J. Immunol. 181, 4452-4456 (2008).

108. Nagarajan, N.A. \& Kronenberg, M. Invariant NKT cells amplify the innate immune response to lipopolysaccharide. J. Immunol. 178, 2706-2713 (2007).

109. Agea, E. et al. Human CD1-restricted T cell recognition of lipids from pollens. J. Exp. Med. 202, 295-308 (2005).

110. Letuve, S. et al. IL-17E upregulates the expression of proinflammatory cytokines in lung fibroblasts. J. Allergy Clin. Immunol. 117, 590-596 (2006).

111. Owyang, A.M. et al. Interleukin 25 regulates type 2 cytokine-dependent immunity and limits chronic inflammation in the gastrointestinal tract. J. Exp. Med. 203, 843-849 (2006).

112. Fort, M.M. et al. IL-25 induces IL-4, IL-5, and IL-13 and Th2-associated pathologies in vivo. Immunity 15, 985-995 (2001).

113. Angkasekwinai, P. et al. Interleukin 25 promotes the initiation of proallergic type 2 responses. J. Exp. Med. 204, 1509-1517 (2007).

114. Tamachi, T. et al. IL-25 enhances allergic airway inflammation by amplifying a TH2 cell-dependent pathway in mice. J. Allergy Clin. Immunol. 118, 606-614 (2006).

115. Ballantyne, S.J. et al. Blocking IL-25 prevents airway hyperresponsiveness in allergic asthma. J. Allergy Clin. Immunol. 120, 1324-1331 (2007).

116. Terashima, A. et al. A novel subset of mouse NKT cells bearing the IL-17 receptor $B$ responds to IL-25 and contributes to airway hyperreactivity. J. Exp. Med. 205, 2727-2733 (2008).

117. Stock, P., Lombardi, V., Kohlrautz, V. \& Akbari, O. Induction of airway hyperreactivity by IL-25 is dependent on a subset of invariant NKT cells expressing IL-17RB. J. Immunol. 182, 5116-5122 (2009).

118. Schmitz, J. et al. IL-33, an interleukin-1-like cytokine that signals via the IL-1 receptor-related protein ST2 and induces Thelper type 2associated cytokines. Immunity 23, 479-490 (2005).

119. Baekkevold, E.S. et al. Molecular characterization of NF-HEV, a nuclear factor preferentially expressed in human high endothelial venules. Am. J. Pathol. 163, 69-79 (2003).

120. Kondo, Y. et al. Administration of IL-33 induces airway hyperresponsiveness and goblet cell hyperplasia in the lungs in the absence of adaptive immune system. Int. Immunol. 20, 791-800 (2008).

121. Bourgeois, E. et al. The pro-Th2 cytokine IL-33 directly interacts with invariant NKT and NK cells to induce IFN-gamma production. Eur. J. Immunol. 39, 1046-1055 (2009).

122. Smithgall, M.D., Comeau, M.R., Yoon, B.R., Kaufman, D., Armitage, R. \& Smith, D.E. IL-33 amplifies both Th1- and Th2-type responses through its activity on human basophils, allergen-reactive Th2 cells, iNKT and NK cells. Int. Immunol. 20, 1019-1030 (2008).

123. Liu, Y.J. TSLP in epithelial cell and dendritic cell cross talk. Adv. Immunol. 101, 1-25 (2009).

124. Liu, Y.J. et al. TSLP: an epithelial cell cytokine that regulates T cell differentiation by conditioning dendritic cell maturation. Annu. Rev. Immunol. 25, 193-219 (2007).

125. Watanabe, N., Hanabuchi, S., Marloie-Provost, M.A., Antonenko, S., Liu, Y.J. \& Soumelis, V. Human TSLP promotes CD40 ligand-induced IL-12 production by myeloid dendritic cells but maintains their Th2 priming potential. Blood 105, 4749-4751 (2005).
126. Nagata, Y., Kamijuku, H., Taniguchi, M., Ziegler, S. \& Seino, K. Differential role of thymic stromal lymphopoietin in the induction of airway hyperreactivity and Th2 immune response in antigen-induced asthma with respect to natural killer T cell function. Int. Arch. Allergy Immunol. 144, 305-314 (2007).

127. Meylan, F. et al. The TNF-family receptor DR3 is essential for diverse T cell-mediated inflammatory diseases. Immunity 29, 79-89 (2008).

128. Fang, L., Adkins, B., Deyev, V. \& Podack, E.R. Essential role of TNF receptor superfamily 25 (TNFRSF25) in the development of allergic lung inflammation. J. Exp. Med. 205, 1037-1048 (2008).

129. Akbari, O. et al. ICOS/ICOSL interaction is required for CD4+ invariant NKT cell function and homeostatic survival. J. Immunol. 180, 5448-5456 (2008).

130. Yoshimoto, T. et al. Nonredundant roles for CD1d-restricted natural killer T cells and conventional CD4+ T cells in the induction of immunoglobulin E antibodies in response to interleukin 18 treatment of mice. J. Exp. Med. 197, 997-1005 (2003).

131. Yamagata, S., Tomita, K., Sato, R., Niwa, A., Higashino, H. \& Tohda, Y. Interleukin-18-deficient mice exhibit diminished chronic inflammation and airway remodelling in ovalbumin-induced asthma model. Clin. Exp. Immunol. 154, 295-304 (2008).

132. Hachem, P. et al. Alpha-galactosylceramide-induced iNKT cells suppress experimental allergic asthma in sensitized mice: role of IFNgamma. Eur. J. Immunol. 35, 2793-2802 (2005).

133. Matsuda, H. et al. alpha-Galactosylceramide, a ligand of natural killer $T$ cells, inhibits allergic airway inflammation. Am. J. Respir. Cell Mol. Biol. 33, 22-31 (2005).

134. Morishima, Y. et al. Suppression of eosinophilic airway inflammation by treatment with alpha-galactosylceramide. Eur. J. Immunol. 35, 28032814 (2005).

135. Dombrowicz, D. Exploiting the innate immune system to control allergic asthma. Eur. J. Immunol. 35, 2786-2788 (2005).

136. Kawano, T. et al. Natural killer-like nonspecific tumor cell lysis mediated by specific ligand-activated Valpha14 NKT cells. Proc. Natl. Acad. Sci. USA 95, 5690-5693 (1998).

137. Toura, I., Kawano, T., Akutsu, Y., Nakayama, T., Ochiai, T. \& Taniguchi, M. Cutting edge: inhibition of experimental tumor metastasis by dendritic cells pulsed with alpha-galactosylceramide. J. Immunol. 163, 23872391 (1999).

138. Nagaraj, S., Ziske, C., Strehl, J., Messmer, D., Sauerbruch, T. \& Schmidt-Wolf, I.G. Dendritic cells pulsed with alpha-galactosylceramide induce anti-tumor immunity against pancreatic cancer in vivo. Int. Immunol. 18, 1279-1283 (2006).

139. Hayakawa, Y., Rovero, S., Forni, G. \& Smyth, M.J. Alpha-galactosylceramide (KRN7000) suppression of chemical- and oncogene-dependent carcinogenesis. Proc. Natl. Acad. Sci. USA 100, 9464-9469 (2003).

140. Fujii, S., Shimizu, K., Kronenberg, M. \& Steinman, R.M. Prolonged IFN-gamma-producing NKT response induced with alphagalactosylceramide-loaded DCs. Nat. Immunol. 3, 867-874 (2002).

141. Ishikawa, A. et al. A phase I study of alpha-galactosylceramide (KRN7000)-pulsed dendritic cells in patients with advanced and recurrent non-small cell lung cancer. Clin. Cancer Res. 11, 1910-1917 (2005).

142. Okai, M. et al. Human peripheral blood Valpha24+ Vbeta11+ NKT cells expand following administration of alpha-galactosylceramide-pulsed dendritic cells. Vox. Sang. 83, 250-253 (2002).

143. Uchida, T. et al. Phase I study of alpha-galactosylceramide-pulsed antigen presenting cells administration to the nasal submucosa in unresectable or recurrent head and neck cancer. Cancer Immunol. Immunother. 57, 337-345 (2008).

144. Fujii, S. et al. Glycolipid alpha-C-galactosylceramide is a distinct inducer of dendritic cell function during innate and adaptive immune responses of mice. Proc. Natl. Acad. Sci. USA (2006)\#\#103, $11252-11257$.

145. Schmieg, J., Yang, G., Franck, R.W. \& Tsuji, M. Superior protection against malaria and melanoma metastases by a C-glycoside analogue of the natural killer T cell ligand alpha-galactosylceramide. J. Exp. Med. 198, 1631-1641 (2003).

146. Miyamoto, K., Miyake, S. \& Yamamura, T. A synthetic glycolipid prevents autoimmune encephalomyelitis by inducing $\mathrm{TH} 2$ bias of natural killer $\mathrm{T}$ cells. Nature 413, 531-534 (2001).

147. Oki, S., Chiba, A., Yamamura, T. \& Miyake, S. The clinical implication and molecular mechanism of preferential IL-4 production by modified glycolipid-stimulated NKT cells. J. Clin. Invest. 113, 1631-1640 (2004). 